\title{
Phylogenetic biogeography of Euphrasia section Malesianae (Orobanchaceae) in Taiwan and Malesia
}

\author{
M.-J. Wu' ${ }^{1}$, T.-C. Huang ${ }^{2}$, S.-F. Huang ${ }^{3}$
}

\section{Key words}

biogeography

Euphrasia

phylogeny

rps2 gene sequence

trnL intron sequence

trnL-trnF intergenic spacer sequence

\begin{abstract}
Species of Euphrasia are distributed in both hemispheres with a series of connecting localities on the mountain peaks of Taiwan and the Malesian region including Luzon, Borneo, Sulawesi, Seram and New Guinea. Two hypotheses are proposed to explain this distribution pattern. The Northern Hemisphere might have been the centre of origin or the Southern Hemisphere. This study aims to reconstruct the core phylogeny of Euphrasia in the connecting areas and tries to identify the migratory direction of Euphrasia in Taiwan and Malesia. The phylogeny of Euphrasia, including sections Euphrasia, Malesianae and Pauciflorae, is reconstructed with the chloroplast molecular markers $r p s 2$ gene, $t r n L$ intron and $t r n L-t r n F$ intergenic spacer. The results suggest that the migratory direction between Taiwan and the Philippines is possibly from the north to the south. However, the migratory direction within section Malesianae and the centre of origin of Euphrasia remain unanswered from our data. More data is needed to clarify this issue.
\end{abstract}

Published on 30 October 2009

\section{INTRODUCTION}

Euphrasia contains about 170 species and 14 sections, each with a typical distributional area (Table 1; Barker 1982: f. 19). The section Euphrasia comprises about 90 species widely distributed in the northern temperate areas. Section Atlanticae has two species restricted to the Azores. Section Malesianae contains about 13 species distributed in Taiwan, the Philippines, Borneo and Seram (Ceram). Section Pauciflorae holds about 14 species in the mountain zone of Sulawesi (Celebes), New Guinea and New Zealand. Section Cuneatae has two disjunct species in New Zealand and eastern Australia. The sections Australes, Lasiantherae, Phragmostomae, Scabrae and Striatae, comprising together about 18 species, are endemic to Australia. Sections Anagospermae and Novaezeelandiae, eight species, are restricted to New Zealand. The monotypic section Paradoxae is endemic to the Juan Fernandez Islands. Section Trifidae comprises 18 species restricted to the Andes. Hence the sectional diversity centre is in the Southern Hemisphere and the distribution pattern of the genus is bi-hemispherical with a series of intermediate species on the mountain peaks of Taiwan and Malesian region.

Such a distribution pattern has inspired two theories to explain the possible dispersal mechanism. One theory is that the genus is old and the pattern could have been caused by migration from various places of origin through ancient land bridges (Von Wettstein 1896, Du Rietz 1932, 1948, Van Steenis 1971, Barker 1982). The other theory is that the genus could be young and the pattern could have been the result of long distance dispersal (Raven \& Axelrod 1972, Raven 1973). However, recent studies on most plants in Malesia support the first theory (Morley 1998, Van Welzen et al. 2005). As to the possible centre of origin of Euphrasia, the first theory considers the Southern Hemisphere

\footnotetext{
Graduate Institute of Biological Resources and Technology, National Dong Hwa University, formerly known as National Hualien University of Education, Hualien 970, Taiwan.

2 Institute of Plant Biology, National Taiwan University, Taipei 106, Taiwan.

${ }^{3}$ Department of Applied Science, National Hsinchu University of Education, Hsinchu 300, Taiwan.
}

as the centre of origin (Von Wettstein 1896, Van Steenis 1962, Barker 1982), while the other theory considers it to be in the Northern Hemisphere (Raven \& Axelrod 1972, Raven 1973).

The Malesian region, or the Malay Archipelago, is a natural phytogeographic area with endemic species up to $70 \%$ (Van Steenis 1950, Van Welzen et al. 2005). In the Malesian region the genus Euphrasia is distributed on a series of mountain peaks in Taiwan, Luzon, Borneo, Sulawesi, Seram, New Guinea and New Zealand (Fig. 1). These species belong to sections Malesianae and Pauciflorae. Seven species and one variety in section Malesianae, from the isolated alpine areas of Taiwan, Luzon, Borneo and Seram, were recently studied (Barker 1982, Wu \& Huang 1998, 2004). Several geographical boundaries were drawn between these islands. The first boundary is between Taiwan and Luzon and forms the northern limit of the Malesian region (Van Steenis 1950). The second one is the MerrillDickerson/Huxley line (a variant of Wallace's line) between Luzon and Borneo. The third one is Wallace's line and separates Seram from the Philippines and Borneo. These geographical lines may be tested through phylogenetic studies.

In Taiwan, three species and one variety in section Malesianae were recognized based on morphology (Wu \& Huang 1998).

Table 1 Distribution of Euphrasia which is separated into 14 sections (modified from Barker 1982: f. 19).

\begin{tabular}{lcl}
\hline Section & Number of species & Distribution \\
\hline Anagospermae & 4 & New Zealand \\
Atlanticae & 2 & Azores \\
Australes & 5 & Australia \\
Cuneatae & 2 & Nea Zealand, Australia \\
Euphrasia & \pm 90 & northern temperate areas \\
Lasiantherae & 3 & Australia \\
Malesianae & \pm 13 & Taiwan, Philippines, Borneo, Seram \\
Novaezeelandiae & 4 & New Zealand \\
Paradoxae & 1 & Juan Fernandez Islands \\
Pauciflorae & \pm 14 & Sulawesi, New Guinea, New Zealand \\
Phragmostomae & 1 & Australia \\
Scabrae & 5 & Australia \\
Striatae & 4 & Australia \\
Trifidae & 18 & the Andes \\
\end{tabular}




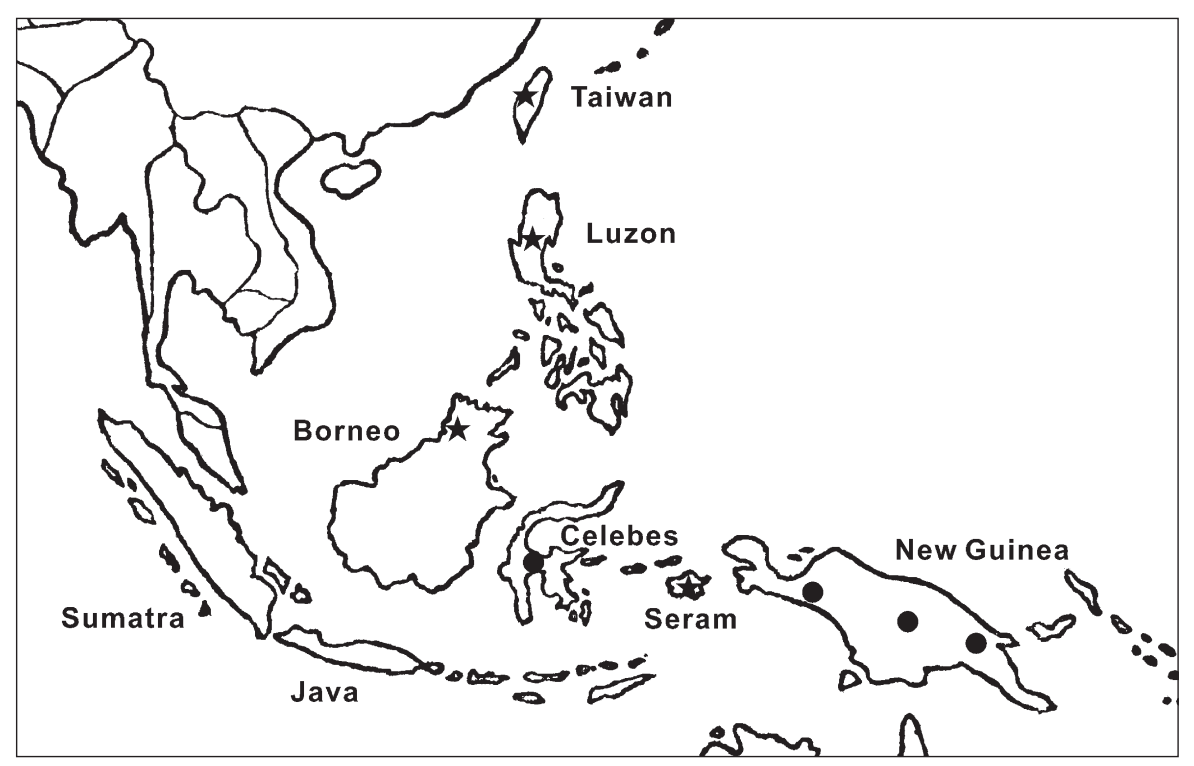

Fig. 1 Distribution of Euphrasia sections Malesianae $(\star)$ and Pauciflorae (๑)in Taiwan and Malesia.

However, it was impossible to distinguish these morphological taxa with the aid of molecular markers of the chloroplast DNA (cpDNA) such as the intron of $t r n L$ gene and intergenic spacer of trnL-trnF, and the nuclear DNA (nrDNA) intergenic spacer (ITS) (Wu \& Huang 2004, Wu et al. 2005). The species were also indistinguishable by pollen and seed morphology. They share tricolpate and spheroidal pollen grains and seed coats with several longitudinal ridges with numerous perpendicular small scalariform ridges (Wu 2004). The basic chromosome number is always $n=11$ (Wu 2004), which also occurs within the sections Euphrasia, Pauciflorae (Barker 1982) and Australes (Barker et al. 1988). Morphologically, section Malesianae closely resembles sections Euphrasia and Atlanticae of the Northern Hemisphere, and they may be derived from the same ancestor as section Pauciflorae, which is distributed from Malesia to New Zealand (Barker 1982: f. 22). This suggests that the Taiwanese species could have been derived from the south, probably from the Philippines. A recent study on Oreomyrrhis (Apiaceae), which has a similar distribution pattern as Euphrasia, suggests a long distance dispersal mechanism, because the genus seems young, and the migratory direction was from Australia to the north in the Old World based on a nrITS haplotype network (Chung et al. 2005). However, the larger part of the temperate vascular flora in Taiwan is derived from continental Asia (Hsieh 2003), thus apparently Oreomyrrhis with its Malesian derival is atypical. Therefore, it is interesting to know from which region Euphrasia species migrated to Taiwan.

In this paper we investigate whether the Euphrasia species in Taiwan are derived from Malesian species (like Oreomyrrhis), or migrated from continental Asia as most temperate species in Taiwan. The two scenarios will be tested with the phylogeny of sections Euphrasia, Malesianae and Pauciflorae. The haplotypes should either be basal to the ones found in section Euphrasia (southern origin) or the haplotypes of sections Malesianae and Pauciflorae are derived from those of section Euphrasia (northern origin).

Table 2 Euphrasia species used for sequencing and their haplotypes ( $r p s 2$, $t r n L-t r n F, r p s 2 \&$ trnL-trnF) recognized in this study.

\begin{tabular}{|c|c|c|c|c|c|}
\hline Taxa & Distribution & rps2 & trnL-trnF & $r p s 2 \&$ trnL-trnF & GenBank accession number \\
\hline Bartsia alpina & Northern hemisphere & $\mathrm{Ba}$ & - & - & U48751 \\
\hline Parentucellia viscosa & Europe & $\mathrm{Pv}$ & - & - & U48753 \\
\hline Tozzia alpina & Europe & $\mathrm{Ta}$ & - & - & U48754 \\
\hline \multicolumn{6}{|l|}{ Section Malesianae } \\
\hline E. borneensis & Borneo & A & $\mathrm{M}, \mathrm{N}$ & $\mathrm{AM}, \mathrm{AN}$ & FJ600675, 676, 682 \\
\hline E. nankotaizanensis & Taiwan & $\mathrm{C}$ & $\mathrm{C}, \mathrm{I}$ & $\mathrm{CC}, \mathrm{Cl}$ & $\begin{array}{l}\text { AY512697, 698, 711, 712, 720-723, 733, 734, } \\
\text { 751, 752, FJ600687 }\end{array}$ \\
\hline E. tarokoana & Taiwan & $\mathrm{C}$ & G & CG & AY512702-705, 775-778, FJ600688 \\
\hline E. transmorisonensis var. transmorisonensis & Taiwan & $\mathrm{C}$ & $\begin{array}{l}A, B, C \\
D, E, F\end{array}$ & $\begin{array}{l}\mathrm{CA}, \mathrm{CB}, \mathrm{CC} \\
\mathrm{CD}, \mathrm{CE}, \mathrm{CF}\end{array}$ & $\begin{array}{l}\text { AY512684-687, 689-691,693, 695, 696, } \\
699-701,706-710,713-719,727-730,738, \\
739,741-750,753-769,772-774\end{array}$ \\
\hline E. transmorisonensis var. duritziana & Taiwan & $\mathrm{B}, \mathrm{C}$ & $\mathrm{KA}, \mathrm{C}, \mathrm{H}, \mathrm{J}$ & $\begin{array}{l}\mathrm{BK}, \mathrm{CA}, \mathrm{CC} \\
\mathrm{CH}, \mathrm{CJ}\end{array}$ & $\begin{array}{l}\text { AY512681-683, 688, 692, 694, 724, 726, 731, } \\
732,735-737,740,770,771, \text { FJ600673 }\end{array}$ \\
\hline \multicolumn{6}{|l|}{ Section Pauciflorae } \\
\hline E. mirabilis & Papua New Guinea & D & $\mathrm{O}$ & DO & FJ600672, 690 \\
\hline \multicolumn{6}{|l|}{ Section Euphrasia } \\
\hline E. hirtella & Georgia & $E$ & $\mathrm{Y}$ & EY & AY831432, FJ600689 \\
\hline E. maximowiczii & Japan & $E$ & $\mathrm{R}$ & ER & FJ600677, 691 \\
\hline E. officinalis & UK & G & - & - & FJ600676 \\
\hline E. petiolaris & Georgia & $\mathrm{H}$ & $x$ & EX & AY831431, FJ600697 \\
\hline E. picta & Austria & $E$ & $\mathrm{P}$ & $\mathrm{EP}$ & FJ600679, 680 \\
\hline E. spectabilis & Austria & $\mathrm{F}$ & Q & $\mathrm{FQ}$ & FJ600678, 695 \\
\hline E. stricta & Denmark & $\mathrm{E}$ & $\mathrm{P}$ & EP & FJ600681, 693 \\
\hline E. subarctica & Canada & $E$ & - & - & FJ600694 \\
\hline
\end{tabular}




\section{MATERIAL AND METHODS}

\section{Plant material and DNA sequencing}

The sampled species cover sections Malesianae, Euphrasia and Pauciflorae (Table 2). Based on the rps2 gene, 15 taxa of Euphrasia and 10 outgroups from Orobanchaceae and Scrophulariaceae were used to reconstruct the phylogeny. DePamphilis et al. (1997) found that Bartsia alpina, Parentucellia viscosa and Tozzia alpina were the most closely related taxa to Euphrasia. Therefore, Bartsia, Parentucellia and Tozzia were used as outgroups in our analysis (Table 2). Based on trnL-trnF sequences, which includes the partial $t r n \mathrm{~L}$ gene, its intron and the spacer between the genes $t r n \mathrm{~L}$ and $t r n \mathrm{~F}$, a total of 110 samples from Taiwan (part of them based on the data of Wu et al. 2005), 8 samples from Sabah, Borneo, 6 samples from Papua New Guinea, 5 samples from the Philippines, 1-3 samples of 7 species that belong to the section Euphrasia, were analyzed.

Fresh leaves of the Taiwanese species and silica-gel-dried leaves were obtained of E. borneensis, E. maximowicziana, E. mirabilis, E. philippinensis, E. picta and E. stricta. The other leaf material was collected from herbarium specimens. Voucher specimens are listed in Table 2.

The protocol of Doyle \& Doyle (1990) was applied to extract DNA using DNeasy plant mini kit (QIAGEN). The extracted DNA was then amplified by the polymerase chain reaction (PCR). The three cpDNA markers were used in this study, i.e., gene of $r p s 2$, intron of $t r n \mathrm{~L}$ gene, and intergenic spacer of $t r n \mathrm{~L}-t r n \mathrm{~F}$. The primers for trnL-trnL intron were 5'-CGA AAT CGG TAG ACG CTA CG-3' in forward and 5'-GGG GAT AGA GGG ACT TGA AC-3' in reverse; and the primers for trnL-trnF intergenic spacer were 5'-GGT TCAAGT CCC TCT ATC CC-3' in forward and 5'-ATT TGA ACT GGT GAC ACG AG-3' in reverse. The primers for rps2 were 5'-ACC CTC ACA AAT AGC GAA TAC CAA in forward (rps2-47F) and 5, CTC GTT TTT TAT CTG AAG CCT G in reverse (rps2-661R) (DePamphilis et al. 1997).

Thirty-five thermal cycles were used during amplification, with an annealing temperature of $54^{\circ} \mathrm{C}$ for 30 seconds and an extension temperature of $72{ }^{\circ} \mathrm{C}$ for 60 seconds. The PCR products were then purified with a QIAGEN PCR purification kit and sequenced with a model 373A automatic sequencer (Applied Biosystems) using the Big Dye terminator.

\section{Phylogenetic tree analysis}

DNA sequences were examined by using Sequencher 4.1 (Gene Codes Corporation, Ann Arbor, Michigan, USA) and they were aligned by using MacClade 4 software (Maddison \& Maddison 2001). The phylogeny of each gene marker was reconstructed with PAUP 4.10 (Swofford 2000) either using the criterion of maximum Fitch parsimony with heuristic search and TBR swapping algorithm, or using criterion of maximum likelihood with the HKY model. Measures of support for each clade were generated using bootstrap analysis (Felsenstein 1985) with a 1000 replicates.

\section{RESULTS}

Based on the rps2 gene, the strict consensus cladogram (Fig. 2) has a length 487 bps (base pairs) after alignment. No indels (insertion-deletions) were invoked. Thirty-five variation sites were found of which 20 were uninformative and 15 sites were informative (Table 3). Twenty four most parsimonious trees were found with a $\mathrm{Cl}$ index of 0.9118 . The Euphrasia clade was well supported by a bootstrap value (BS) of $100 \%$. The ingroup shows a polytomy with three species, E. borneensis, E. mirabilis and E. petiolaris, and two clades, the larger parts of

Fig. 2 Strict consensus cladogram of 24 most parsimonious cladograms of Euphrasia based on the rps2 dataset. Numbers above the branches are the number of substitutions, and numbers below the branches are the bootstrap values equal or higher than $50 \%$. The haplotypes (Table 3 ) are shown in parentheses.

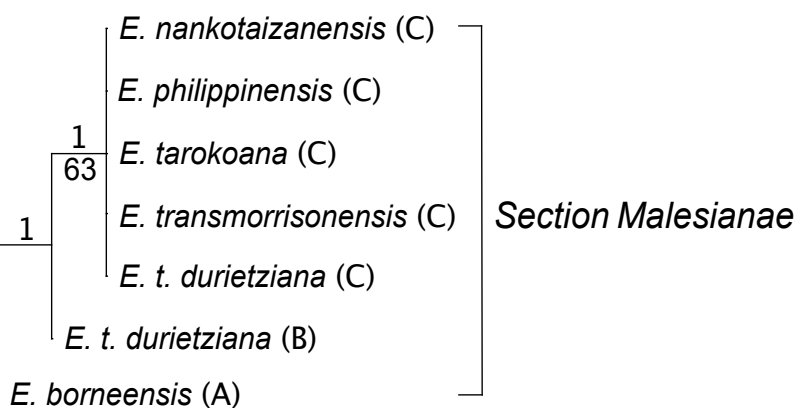

E. borneensis (A)

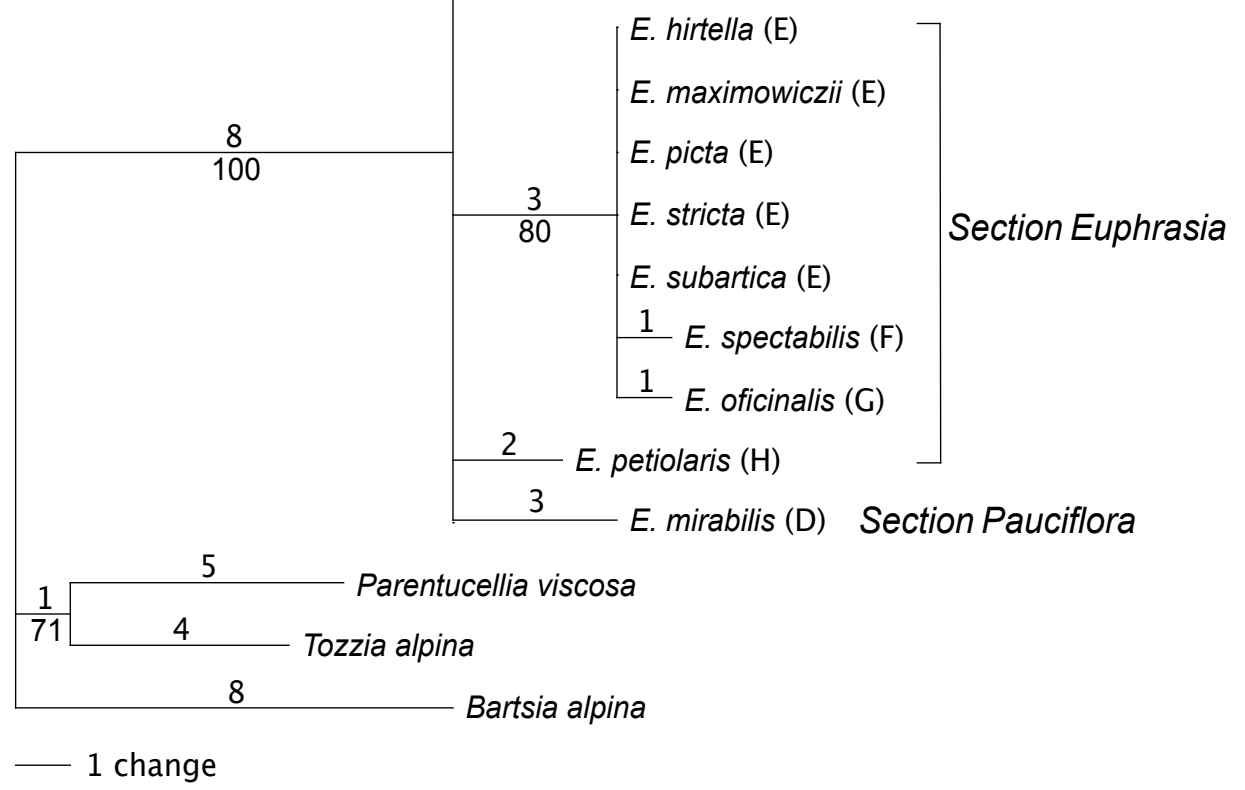


Table 3 Haplotypes $\left(\mathrm{H}^{*}\right)$ of Euphrasia and three related species recognized in the rps2 gene tree based on polymorphic sites. Ba = Bartsia alpina; $\mathrm{Pv}=$ Parentucellia viscosa; Ta = Tozzia alpina.

\begin{tabular}{|c|c|c|c|c|c|c|c|c|c|c|c|c|c|c|c|c|c|c|c|c|c|c|c|c|c|c|c|c|c|c|c|c|c|c|c|}
\hline \multirow{4}{*}{$\mathrm{H}^{*}$} & \multicolumn{35}{|c|}{ Polymorphic site } \\
\hline & 0 & 0 & 0 & 0 & 0 & 1 & 1 & 1 & 1 & 1 & 1 & 1 & 1 & 2 & 2 & 2 & 2 & 2 & 2 & 2 & 2 & 2 & 2 & 2 & 2 & 3 & 3 & 3 & 3 & 3 & 3 & 4 & 4 & 4 & 4 \\
\hline & 0 & 0 & 6 & 7 & 8 & 0 & 0 & 2 & 3 & 5 & 6 & 8 & 8 & 0 & 0 & 1 & 1 & 2 & 4 & 4 & 6 & 6 & 7 & 8 & 9 & 2 & 3 & 5 & 6 & 7 & 7 & 1 & 2 & 6 & 6 \\
\hline & 3 & 7 & 4 & 9 & 1 & 0 & 6 & 4 & 3 & 7 & 6 & 1 & 8 & 7 & 8 & 3 & 4 & 3 & 1 & 8 & 5 & 7 & 7 & 5 & 3 & 5 & 1 & 8 & 4 & 0 & 4 & 8 & 7 & 0 & 9 \\
\hline $\mathrm{Ba}$ & G & G & $A$ & A & C & C & $\mathrm{T}$ & $A$ & C & $\mathrm{T}$ & $\mathrm{G}$ & $A$ & $\mathrm{~T}$ & C & $\mathrm{G}$ & G & $A$ & C & $\mathrm{G}$ & $G$ & $\mathrm{C}$ & $\mathrm{G}$ & $A$ & $G$ & $A$ & $\mathrm{C}$ & $\mathrm{T}$ & $\mathrm{G}$ & $\mathrm{G}$ & $\mathrm{C}$ & $\mathrm{T}$ & C & $A$ & $A$ & $\mathrm{C}$ \\
\hline $\mathrm{PV}$ & A & G & $A$ & $A$ & $\mathrm{~T}$ & C & C & G & C & $\mathrm{T}$ & G & C & C & $C$ & C & C & G & C & $\mathrm{G}$ & G & $\mathrm{G}$ & A & $\mathrm{G}$ & $G$ & $A$ & C & $\mathrm{G}$ & G & $A$ & C & $\mathrm{T}$ & C & $A$ & $A$ & C \\
\hline $\mathrm{Ta}$ & A & $\mathrm{G}$ & $\mathrm{C}$ & $A$ & $\mathrm{~T}$ & C & C & $\mathrm{G}$ & C & $\mathrm{T}$ & $\mathrm{G}$ & $\mathrm{C}$ & $\mathrm{T}$ & C & $\mathrm{G}$ & $\mathrm{G}$ & $A$ & C & $\mathrm{G}$ & $\mathrm{G}$ & $\mathrm{G}$ & A & $\mathrm{G}$ & $A$ & $A$ & C & $\mathrm{G}$ & $\mathrm{G}$ & $\mathrm{G}$ & C & $\mathrm{C}$ & $\mathrm{T}$ & $A$ & $A$ & C \\
\hline$A$ & A & G & $A$ & C & $\mathrm{T}$ & $\mathrm{G}$ & C & G & $\mathrm{T}$ & C & G & C & $\mathrm{T}$ & C & $\mathrm{G}$ & G & $A$ & $A$ & $\mathrm{G}$ & $\mathrm{G}$ & $\mathrm{G}$ & A & $A$ & $G$ & $C$ & $\mathrm{C}$ & $\mathrm{G}$ & C & $\mathrm{G}$ & $\mathrm{T}$ & $\mathrm{T}$ & C & C & $A$ & 0 \\
\hline B & A & $\mathrm{G}$ & $A$ & C & $\mathrm{T}$ & $\mathrm{G}$ & C & $\mathrm{G}$ & $\mathrm{T}$ & C & $\mathrm{G}$ & $\mathrm{C}$ & $\mathrm{T}$ & $\mathrm{T}$ & $\mathrm{G}$ & $\mathrm{G}$ & $A$ & $A$ & $\mathrm{G}$ & $\mathrm{G}$ & $\mathrm{G}$ & A & $A$ & $\mathrm{G}$ & $A$ & $\mathrm{C}$ & $\mathrm{G}$ & $\mathrm{C}$ & $\mathrm{G}$ & $\mathrm{T}$ & $\mathrm{T}$ & C & $\mathrm{C}$ & $A$ & C \\
\hline C & A & $\mathrm{G}$ & A & C & $\mathrm{T}$ & $G$ & C & $\mathrm{G}$ & $\mathrm{T}$ & C & $\mathrm{G}$ & $\mathrm{C}$ & $\mathrm{T}$ & $\mathrm{T}$ & $\mathrm{G}$ & G & $A$ & A & $G$ & $\mathrm{C}$ & $\mathrm{G}$ & A & $A$ & $G$ & $A$ & $\mathrm{C}$ & $G$ & C & $G$ & $\mathrm{~T}$ & $\mathrm{~T}$ & C & C & $A$ & C \\
\hline$D$ & $A$ & G & $A$ & C & $\mathrm{T}$ & G & C & G & $\mathrm{T}$ & $\mathrm{T}$ & C & C & $\mathrm{T}$ & C & $\mathrm{G}$ & G & $A$ & $A$ & G & $\mathrm{G}$ & $\mathrm{G}$ & A & $A$ & $G$ & $A$ & $\mathrm{~T}$ & $\mathrm{G}$ & C & $\mathrm{G}$ & $\mathrm{T}$ & $\mathrm{T}$ & C & C & $A$ & $T$ \\
\hline$E$ & A & A & $A$ & C & $\mathrm{T}$ & $\mathrm{G}$ & C & $\mathrm{G}$ & $\mathrm{T}$ & C & $\mathrm{G}$ & C & $\mathrm{T}$ & C & $\mathrm{G}$ & G & $A$ & $A$ & $G$ & $G$ & $G$ & A & $A$ & $G$ & $A$ & $\mathrm{~T}$ & $G$ & $\mathrm{C}$ & $\mathrm{G}$ & $\mathrm{T}$ & $\mathrm{T}$ & C & C & $A$ & $T$ \\
\hline$F$ & A & $A$ & $A$ & C & $\mathrm{T}$ & $\mathrm{G}$ & C & G & $\mathrm{T}$ & C & G & C & $\mathrm{T}$ & C & $\mathrm{G}$ & G & $A$ & $A$ & $G$ & $\mathrm{G}$ & $\mathrm{G}$ & A & $A$ & $G$ & $A$ & $\mathrm{~T}$ & $\mathrm{G}$ & C & G & $\mathrm{T}$ & $\mathrm{T}$ & C & C & C & $\mathrm{T}$ \\
\hline $\mathrm{G}$ & A & $A$ & $A$ & C & $\mathrm{T}$ & $G$ & C & $\mathrm{G}$ & $\mathrm{T}$ & C & $\mathrm{G}$ & C & $\mathrm{T}$ & C & $\mathrm{G}$ & $G$ & $A$ & $A$ & $A$ & $G$ & $G$ & A & $A$ & $\mathrm{G}$ & $A$ & $\mathrm{~T}$ & $\mathrm{G}$ & C & $\mathrm{G}$ & $\mathrm{T}$ & $\mathrm{T}$ & C & C & $A$ & $\mathrm{~T}$ \\
\hline $\mathrm{H}$ & A & $\mathrm{G}$ & $A$ & C & $\mathrm{T}$ & $\mathrm{G}$ & $\mathrm{T}$ & $\mathrm{G}$ & $\mathrm{T}$ & C & $\mathrm{G}$ & C & $\mathrm{T}$ & C & $\mathrm{G}$ & G & $A$ & $A$ & $G$ & $\mathrm{G}$ & $\mathrm{G}$ & A & $A$ & $\mathrm{G}$ & $\mathrm{C}$ & $\mathrm{C}$ & $\mathrm{G}$ & $\mathrm{C}$ & $\mathrm{G}$ & $\mathrm{T}$ & $\mathrm{T}$ & C & C & $A$ & 0 \\
\hline
\end{tabular}

Table 4 Euphrsia haplotypes $\left(\mathrm{H}^{*}\right)$ recognized in the trnL-trnF gene tree based on polymorphic sites.

\begin{tabular}{|c|c|c|c|c|c|c|c|c|c|c|c|c|c|c|c|c|c|c|c|c|c|c|c|c|c|c|c|c|c|c|c|c|c|}
\hline \multirow{4}{*}{$\mathrm{H}^{*}$} & \multicolumn{33}{|c|}{ Polymorphic site } \\
\hline & 0 & 0 & 0 & 0 & 1 & 2 & 2 & 3 & 3 & 3 & 3 & 3 & 4 & 4 & 4 & 5 & 5 & 5 & 5 & 5 & 6 & 6 & 6 & 6 & 6 & 6 & 6 & 6 & 7 & 7 & 7 & 8 & 8 \\
\hline & 1 & 1 & 5 & 9 & 8 & 7 & 8 & 0 & 5 & 8 & 8 & 9 & 2 & 2 & 7 & 3 & 3 & 3 & 4 & 5 & 0 & 0 & 0 & 3 & 3 & 4 & 6 & 7 & 4 & 8 & 9 & 3 & 6 \\
\hline & 3 & 5 & 7 & 6 & 4 & 5 & 5 & 0 & 1 & 3 & 4 & 2 & 2 & 5 & 5 & 4 & 6 & 7 & 4 & 6 & 0 & 4 & 5 & 5 & 7 & 5 & 1 & 2 & 5 & 6 & 5 & 9 & 8 \\
\hline A & $A$ & A & $A$ & $A$ & A & C & $A$ & $\mathrm{G}$ & $\mathrm{T}$ & A & $A$ & C & $C$ & $\mathrm{G}$ & $\mathrm{T}$ & C & $A$ & A & $A$ & $\mathrm{~T}$ & $A$ & $\mathrm{~T}$ & $\mathrm{~T}$ & $\mathrm{~T}$ & C & $A$ & C & $\mathrm{T}$ & $\mathrm{T}$ & $\mathrm{G}$ & C & C & C \\
\hline B & $A$ & A & A & $A$ & A & C & A & G & $\mathrm{T}$ & A & $A$ & C & C & G & $\mathrm{T}$ & C & A & A & A & $\mathrm{T}$ & G & $\mathrm{T}$ & $\mathrm{T}$ & $\mathrm{T}$ & C & $A$ & $\mathrm{C}$ & $\mathrm{T}$ & $\mathrm{T}$ & G & C & C & C \\
\hline C & A & A & A & $A$ & A & C & A & G & $\mathrm{T}$ & A & $A$ & C & C & G & $\mathrm{T}$ & C & A & A & A & $\mathrm{T}$ & C & $\mathrm{T}$ & $\mathrm{T}$ & $\mathrm{T}$ & C & $A$ & C & $\mathrm{T}$ & $\mathrm{T}$ & $\mathrm{G}$ & C & C & C \\
\hline D & $A$ & A & $A$ & $A$ & A & C & A & $\mathrm{G}$ & $\mathrm{T}$ & A & $A$ & C & $C$ & $\mathrm{G}$ & $\mathrm{T}$ & C & $A$ & A & $A$ & $\mathrm{~T}$ & $A$ & $\mathrm{~T}$ & $\mathrm{~T}$ & $G$ & C & $A$ & C & $\mathrm{T}$ & $\mathrm{T}$ & $G$ & C & C & C \\
\hline E & A & A & A & A & A & C & A & G & $\mathrm{T}$ & A & A & C & C & G & $\mathrm{T}$ & C & A & A & A & $\mathrm{T}$ & $A$ & $\mathrm{~T}$ & $\mathrm{~T}$ & $\mathrm{~T}$ & C & $A$ & C & $\mathrm{T}$ & $\mathrm{T}$ & A & C & C & C \\
\hline$F$ & $A$ & A & $A$ & $A$ & A & C & A & $\mathrm{G}$ & $\mathrm{T}$ & A & $A$ & C & C & $\mathrm{G}$ & $\mathrm{T}$ & C & $A$ & A & $A$ & C & $A$ & $\mathrm{~T}$ & $\mathrm{~T}$ & $\mathrm{~T}$ & C & $A$ & C & $\mathrm{T}$ & $\mathrm{T}$ & $G$ & C & C & C \\
\hline G & A & A & $A$ & A & A & A & A & G & $\mathrm{T}$ & A & A & C & C & G & $\mathrm{T}$ & C & $A$ & A & A & $\mathrm{T}$ & C & $\mathrm{T}$ & $\mathrm{T}$ & $\mathrm{T}$ & C & $A$ & C & $\mathrm{T}$ & $\mathrm{T}$ & G & C & C & C \\
\hline $\mathrm{H}$ & A & A & A & A & A & C & A & G & $\mathrm{T}$ & A & A & C & C & G & $\mathrm{T}$ & C & A & A & C & $\mathrm{T}$ & C & $\mathrm{T}$ & $\mathrm{T}$ & $\mathrm{T}$ & C & A & C & $\mathrm{T}$ & $\mathrm{T}$ & $\mathrm{G}$ & C & C & C \\
\hline I & $A$ & A & $A$ & $A$ & A & C & $A$ & $\mathrm{G}$ & C & A & $A$ & C & C & $\mathrm{G}$ & $\mathrm{G}$ & C & $A$ & A & $A$ & $\mathrm{~T}$ & C & $\mathrm{T}$ & $\mathrm{T}$ & $\mathrm{T}$ & $\mathrm{C}$ & $A$ & C & $\mathrm{T}$ & $\mathrm{T}$ & $\mathrm{G}$ & $\mathrm{C}$ & $\mathrm{C}$ & C \\
\hline $\mathrm{J}$ & $A$ & A & $A$ & $A$ & A & C & $A$ & G & $\mathrm{T}$ & A & $A$ & C & C & $\mathrm{G}$ & $\mathrm{T}$ & C & $A$ & $A$ & $A$ & $\mathrm{~T}$ & C & $\mathrm{T}$ & $\mathrm{T}$ & $\mathrm{T}$ & C & $A$ & C & $\mathrm{T}$ & $\mathrm{T}$ & $G$ & C & C & G \\
\hline K & $A$ & $A$ & $A$ & $A$ & A & C & $\mathrm{G}$ & $\mathrm{G}$ & $\mathrm{T}$ & $A$ & $A$ & C & C & $\mathrm{G}$ & $\mathrm{T}$ & C & $A$ & $A$ & $A$ & $\mathrm{~T}$ & $A$ & $\mathrm{~T}$ & $\mathrm{~T}$ & $\mathrm{~T}$ & C & $A$ & $C$ & $\mathrm{~T}$ & $\mathrm{~T}$ & $\mathrm{G}$ & C & C & C \\
\hline L & $A$ & A & C & A & A & C & G & G & $\mathrm{T}$ & A & A & C & C & $\mathrm{G}$ & $\mathrm{T}$ & C & A & A & A & $\mathrm{T}$ & $A$ & $\mathrm{~T}$ & $\mathrm{~T}$ & $\mathrm{G}$ & C & $A$ & C & $\mathrm{T}$ & $\mathrm{T}$ & $\mathrm{G}$ & C & C & C \\
\hline M & $A$ & A & $A$ & A & A & C & G & G & $\mathrm{T}$ & A & A & A & C & G & $\mathrm{T}$ & C & A & A & A & $\mathrm{T}$ & $A$ & $\mathrm{~T}$ & $\mathrm{~T}$ & $\mathrm{~T}$ & C & C & C & $\mathrm{T}$ & $\mathrm{T}$ & G & C & $\mathrm{T}$ & C \\
\hline $\mathrm{N}$ & $A$ & A & $A$ & $A$ & A & C & G & G & $\mathrm{T}$ & A & A & $A$ & C & $\mathrm{G}$ & $\mathrm{T}$ & C & A & A & $A$ & $\mathrm{~T}$ & $A$ & $\mathrm{~T}$ & $\mathrm{~T}$ & $\mathrm{~T}$ & C & C & C & $\mathrm{T}$ & $\mathrm{T}$ & $\mathrm{G}$ & C & C & C \\
\hline 0 & C & C & $A$ & $A$ & A & C & G & $\mathrm{G}$ & $\mathrm{T}$ & G & A & $A$ & C & $\mathrm{G}$ & $\mathrm{T}$ & C & $A$ & A & $A$ & $\mathrm{~T}$ & $A$ & $\mathrm{~T}$ & $\mathrm{~T}$ & $\mathrm{~T}$ & C & $A$ & $\mathrm{~T}$ & $\mathrm{~T}$ & $\mathrm{~T}$ & $G$ & C & C & C \\
\hline $\mathrm{P}$ & $A$ & A & $A$ & C & C & C & G & $\mathrm{G}$ & $\mathrm{T}$ & G & G & $A$ & C & $A$ & $\mathrm{~T}$ & C & $A$ & $A$ & $A$ & $\mathrm{~T}$ & $A$ & $\mathrm{~T}$ & $\mathrm{~T}$ & $\mathrm{~T}$ & $\mathrm{C}$ & $A$ & C & $\mathrm{T}$ & $\mathrm{T}$ & $\mathrm{G}$ & C & C & C \\
\hline Q & $A$ & $A$ & A & C & C & C & $\mathrm{G}$ & $\mathrm{T}$ & $\mathrm{T}$ & G & $\mathrm{G}$ & $A$ & C & $A$ & $\mathrm{~T}$ & C & C & A & $A$ & $\mathrm{~T}$ & $A$ & $\mathrm{~T}$ & $\mathrm{~T}$ & $\mathrm{~T}$ & C & $A$ & C & $\mathrm{T}$ & $\mathrm{T}$ & $\mathrm{G}$ & C & C & C \\
\hline $\mathrm{R}$ & $A$ & $A$ & A & $\mathrm{C}$ & C & C & G & G & $\mathrm{T}$ & G & $A$ & $A$ & C & $A$ & $\mathrm{~T}$ & C & $A$ & $A$ & $A$ & $\mathrm{~T}$ & $A$ & $\mathrm{~T}$ & $\mathrm{~T}$ & $\mathrm{~T}$ & $C$ & $A$ & C & $\mathrm{T}$ & $\mathrm{C}$ & $G$ & C & C & C \\
\hline S & $A$ & A & $A$ & C & C & C & G & G & $\mathrm{T}$ & G & $\mathrm{G}$ & A & C & $A$ & $\mathrm{~T}$ & C & A & $\mathrm{T}$ & A & $\mathrm{T}$ & $A$ & $\mathrm{~T}$ & $\mathrm{~T}$ & $\mathrm{~T}$ & $\mathrm{~T}$ & $A$ & C & $\mathrm{T}$ & $\mathrm{T}$ & G & C & C & C \\
\hline$X$ & $A$ & $A$ & $A$ & $A$ & A & C & G & G & $\mathrm{T}$ & G & $A$ & $A$ & $\mathrm{~T}$ & G & $\mathrm{T}$ & $\mathrm{T}$ & A & A & A & $\mathrm{T}$ & $A$ & $\mathrm{G}$ & G & $\mathrm{T}$ & C & A & C & $A$ & $\mathrm{~T}$ & G & $\mathrm{T}$ & C & C \\
\hline$Y$ & $A$ & $A$ & $A$ & $\mathrm{C}$ & C & C & G & G & $\mathrm{T}$ & G & $\mathrm{G}$ & $A$ & C & $A$ & $\mathrm{~T}$ & C & $A$ & $\mathrm{~T}$ & A & $\mathrm{T}$ & $A$ & $\mathrm{~T}$ & $\mathrm{~T}$ & $\mathrm{~T}$ & C & $A$ & C & $\mathrm{T}$ & $\mathrm{T}$ & $\mathrm{G}$ & C & C & C \\
\hline
\end{tabular}

section Malesianae and section Euphrasia. There were only two substitutions within the clade of section Euphrasia, with a further substitution in E. officinalis and another one in $E$. spectabilis. Two substitutions occurred in section Malesianane.

Based on the trnL-trnF dataset, the total length of the alignment was 903 bps when indels were excluded from analysis. Thirty three variation sites were found of which 21 were uninformative and 12 informative (Table 4). Fifteen most parsimonious trees with $\mathrm{a} \mathrm{Cl}=0.9697$ were found. Euphrasia mirabilis was selected as outgroup. The mark \# is given in Fig. 3 when E. transmorrisonensis var. transmorrisonensis and E. transmorrisonensis var. duritziana share the same haplotype. The strict consensus cladogram (Fig. 3) shows a basal trichotomy of E. petiolaris and two clades, section Malesianae (BS 63) and the majority of section Euphrasia (BS 96). The topology of the tree is similar to the rps2 gene tree (Fig. 2), except for E. borneensis, which is grouped in section Malesianae (Fig. 3) as sister species to the remaining taxa. While the Philippine species with haplotype $L$ is nested inside the Taiwanese haplotypes.

The analysis of the combined rps2 and trnL-trnF datasets (insufficiently known taxa were excluded, E. mirabilis as outgroup) showed a total alignment length of 1400 bps (indels were excluded) and 36 variation sites (19 sites uninformative,
17 informative). The mark \# is given in Fig. 4 when E. transmorrisonensis var. transmorrisonensis and E. transmorrisonensis var. duritziana share the same haplotype. Twelve most parsimonious trees were obtained (strict consensus cladogram in Fig. 4). Section Euphrasia formed a clade (BS 99), just like section Malesianae (BS 86). The maximum likelihood analysis resulted in a similar topology (data not shown) with both sections monophyletic. The Philippine haplotype was again clearly nested inside the Taiwanese species, although the relationship was not well resolved. In the section Malesianae clade E. borneensis is sister species to the remaining species of the clade, the next sister group relation is between $E$. transmorrisonensis var. duritziana (haplotype BK) and the others.

\section{DISCUSSION}

\section{Migratory direction of Euphrasia between Taiwan and Malesia}

Section Malesianae is monophyletic in the trnL-trnF gene tree (Fig. 3) and the combined tree (Fig. 4). This is not contradicted by the rps2 gene tree (Fig. 2) that is partly unresolved (E. borneensis in a basal polytomy). Euphrasia borneensis from Borneo contains the most primitive haplotype of section Malesianae 
Fig. 3 Strict consensus cladogram of 15 most parsimonious cladograms of Euphrasia based on the trnL-trnF dataset. Numbers above the branches are the number of substitutions, and numbers below the branches are the bootstrap values equal or higher than $50 \%$. The mark \# indicates that E. transmorrisonensis var. duritziana shares the same haplotype. The haplotypes (Table 4) are shown in parentheses.



Fig. 4 Strict consensus cladogram of 12 most parsimonious cladograms of Euphrasia based on the combined rps2 and trnL-trnF datasets. The tree topology is the same as those generated by the maximum likelihood criterion under the HKY model. Numbers above the branches are the number of substitutions, and numbers below the branches are the bootstrap values equal or higher than $50 \%$. The mark \# indicates that $E$. transmorrisonensis var. duritziana shares the same haplotype. The haplotypes are shown in parentheses with the first position for the rps2 haplotype (Table 3), and the second position for the trnL-trnF haplotype (Table 4).

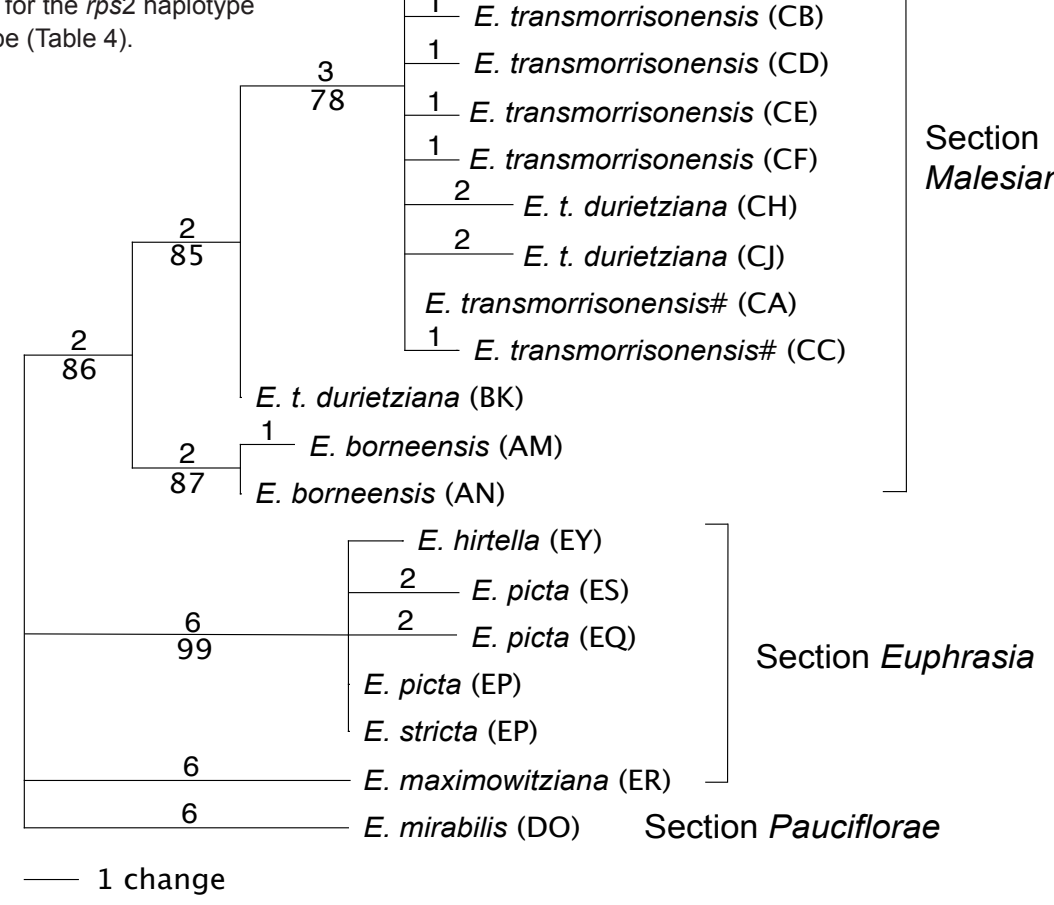

in the rps2 gene tree (Fig. 2) and the trnL-trnF and combined data gene trees. Euphrasia borneensis is sister species to the remaining species of section Malesianae (Fig. 3, 4). If we regard the relationships among sections Euphrasia, Malesianae and Pauciflorae, then section Malesianae has the same genetic distance both with Euphrasia and Pauciflorae. Because Euphrasia transmorrisonensis var. duritziana from Taiwan and E. borneensis from Borneo (both section Malesianae) have the same genetic distance in common with sections Pauciflorae and Euphrasia, the combined gene tree (Fig. 4) shows 10 substitu- tions between sections Malesianae and Pauciflorae, and also between sections Malesianae and Euphrasia. Therefore, the migratory direction of the section Malesianae cannot be inferred from this result. However, the Philippine species contains haplotypes ( $C$ from rps2 tree, $C L$ from combined tree) that could be derived from $E$. transmorrisonensis var. duritziana (B from $r p s 2$ tree, BK from combined tree), or from E. transmorrisonensis (C from rps2 tree, CA from combined tree). Thus the migratory direction between Taiwan and the Philippines was possibly from the north to the south. 


\section{How the Taiwanese species connect with the Philippine species}

Based on the combined data gene tree (Fig. 4), the haplotype of the Philippines (CL) differs from the closest Taiwanese haplotype (CA) in only two substitutions, while there are at least four substitutions between the haplotypes of the Borneo (AN) and Taiwan (BK). Therefore, isolation between Taiwanese and the Philippine species was probably for a relatively short period of time.

The Bashi Strait separates Taiwan from the Philippines. No land bridge ever occurred between both areas, because a trench is running through the strait. Thus the similarity in flora between these two areas should be due either to 1) long distance dispersal between Taiwan and the Philippines; or 2) the same ancestral population in continental Asia migrated to each area independently. The populations in continental Asia belong to section Euphrasia while the populations in Taiwan and the Philippines belong to section Malesianae. This does not support the idea of a shared ancestral population having migrated to each area separately. Our own data also suggests a migratory direction from Taiwan to the Philippines. Hence, the connection between Taiwan and the Philippines should be due to long distance dispersal.

The seeds of Taiwanese Euphrasia species are small but not minute, 1-1.5 mm long (Wu 2004). They might be transported over a long distance by strong winds such as typhoons or monsoon winds. Typhoons before landing on the Philippines and Taiwan usually bring a strong north wind that could facilitate dispersal. The prevailing northeast winter monsoons also generate optimum winds for seed transport from Taiwan to the Philippines. Another possibility is transport by migrating birds. The plants of Euphrasia in Taiwan inhabit rock slits on mountain slopes, or occur in wet flat, sometimes marshy places. When migrating birds take a rest in the mountains of Taiwan during their flight to the south to avoid the winter cold, the seeds of Euphrasia species in marshy habitats may be imbedded in the mud, which may get stuck to the legs of the birds and is thus carried by them to the south (Raven 1973). Plants of Euphrasia are hemiparasitic and they can establish on a wide range of host plants. Therefore, establishments of new populations is likely even without the normally associated plants (Wilkins 1963).

Our data indicates direct dispersal from Taiwan to the Philippines based on the phylogeny of section Malesianae, and the long distance dispersal is likely due to strong winds or avian migration.

\section{Possible center of origin of Euphrasia}

Our data are insufficient to explain the migratory direction of section Malesianae in the Malesian region. Therefore, it is also still too early to propose a centre of origin.

Acknowledgements The authors are greatly thankful to Prof. Peter van Welzen for providing advice and improving their English, and appreciate Dr. Tomoyuki Nemoto for providing samples of Euphrasia maximowiczii, Mr. Leonardo L. Co for providing samples of E. philippinensis, and to Dr. Finn Borchsenius for providing samples of E. stricta. Thanks also to the following people for their help on the field trips: Dr. Roy Banka and Mr. Tory Kuria (Herbarium LAE, Papua New Guinea); Dr. Jamili Nais and Ms Remi Repin (Herbarium SNP, Malaysia); and Dr. Daniel Lagunzad and Mr. Leonardo L. Co (Herbarium PUH). This work was funded by the grant NSC 94-2313-B134-001, NSC 95-2621-B-026-001 and NSC 96-2621-B-026-001-MY3.

\section{REFERENCES}

Barker WR. 1982. Taxonomy studies in Euphrasia L. (Scrophulariaceae). A revised infrageneric classification, and a revision of the genus in Australia. Journal of the Adelaide Botanic Gardens 5: 1-304.

Barker WR, Kiehn M, Vitek E. 1988. Chromosome numbers in Australian Euphrasia (Scrophulariaceae). Plant Systematics and Evolution 158: 161-164

Chung KF, Peng Cl, Downie SR, Spalik K, Schaal BA. 2005. Molecular systematics of the trans-pacific alpine genus Oreomyrrhis (Apiaceae): phylogenetic affinities and biogeographic implications. American Journal of Botany 92: 2054-2071.

DePamphilis CW, Young ND, Wolfe AD. 1997. Evolution of plastid gene rps2 in a lineage of hemiparasitic and holoparasitic plants: Many losses of photosynthesis and complex patterns of rate variation. Proceedings of the National Academy of Sciences of the United States of America 94: 73677372.

Doyle JJ, Doyle JL. 1990. Isolation of plant DNA from fresh tissue. Focus 12: $13-15$.

Du Rietz GE. 1932. Two new species of Euphrasia from the Philippines and their phytogeographical significance. Svensk Botanisk Tidskrift Utgifven af Svenska Botaniska Foreningen 25: 500-542.

Du Rietz GE. 1948. Taxonomical notes on some Tasmanian species of Euphrasia. I. Euphrasia striata R.Br. and E. gibbsiae Du Rietz n.sp. Svensk Botanisk Tidskrift Utgifven af Svenska Botaniska Foreningen 42: 99-115.

Felsenstein J. 1985. Confidence limits on phylogenies: An approach using the bootstrap. Evolution 39: 783-791.

Hsieh C-F. 2003. Composition, endemism and phytogeographical affinities of the Taiwan Flora. Flora of Taiwan, ed. 2, vol. 6. National Taiwan University, Taipei.

Maddison DR, Maddison WP. 2001. MacClade 4: Analysis of Phylogeny and Character Evolution. Version 4.03. Sinauer Associates, Sunderland, Massachusetts.

Morley RJ. 1998. Palynological evidence for Tertiary plant dispersals in the SE Asian region in relation to plate tectonics and climate. In: Hall R, Holloway JD (eds), Biogeography and Geological Evolution of SE Asia: 211-234. Backhuys Publishers, Leiden, The Netherlands.

Raven PH. 1973. Evolution of subalpine and alpine plant groups in New Zealand. New Zealand Journal of Botany 11: 177-200.

Raven PH, Axelrod DI. 1972. Plant tectonics and Australasian paleogeography. Science 176: 1379-1386.

Swofford DL. 2000. Phylogenetic Analysis Using Parsimony (and other methods). Version 4. Sinauer Associates, Sunderland, Massachusetts.

Van Steenis CGGJ. 1950. The delimitation of Malaysia and its main plant geographical divisions. Flora Malesiana, Ser. I, Vol. 1: 70-75.

Van Steenis CGGJ. 1962. The land-bridge theory in botany. Blumea 11: 235-542.

Van Steenis CGGJ. 1971. Distribution and ecology of Northofagus, living and fossil, with suggestions on its cradle and age. Papua and New Guinea Scientific Society Proceedings 22: 15-20.

Van Welzen PC, Slik JWF, Alahuhta J. 2005. Plant distribution pattern and plate tectonics in Malesia. Biologiske Skrifter 55: 199-217.

Von Wettstein R. 1896. Monographiae der gattung Euphrasia. Engelmann, Leipzig.

Wilkins DA. 1963. Plasticity and establishment in Euphrasia. Annals of Botany 27: 533-553.

Wu M-J. 2004. A biosystematic study on Euphrasia L. (Scrophulariaceae) in Taiwan. Doctoral thesis, Institute of Plant Biology, National Taiwan University, Taipei.

Wu M-J, Huang SF, Huang TC, Lee PF, Lin TP. 2005. Evolution of Euphrasia transmorrisonensis complex (Orobanchaceae) in alpine areas of Taiwan. Journal of Biogeography 32: 1921-1929.

Wu M-J, Huang TC. 1998. Euphrasia L. In: Huang TC, Hsieh CF, Boufford DE, Lowry PP II, Ohashi H, Peng Cl, Yang SY, Hsiao A, Lin HW, Yu CL (eds), Flora of Taiwan 4: 591-597. Department of Botany, National Taiwan University, Taipei.

Wu M-J, Huang TC. 2004. Taxonomy of the Euphrasia transmorrisonensis (Orobanchaceae) complex in Taiwan based on nrlTS. Taxon 53: 911-918. 
